
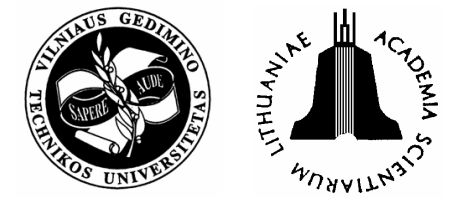

\title{
IMPROVEMENT OF URBAN PASSENGER TRANSPORT TICKETING SYSTEMS BY DEPLOYING INTELLIGENT TRANSPORT SYSTEMS
}

\author{
Gražvydas Jakubauskas \\ Dept of Transport Management, Vilnius Gediminas Technical University, \\ Plytinès g. 27, LT-10105 Vilnius, Lithuania. Phone +370 52744780. \\ E-mail: Grazvydas.Jakubauskas@ti.vtu.lt
}

Received 2 May 2006; accepted 4 September 2006

\begin{abstract}
The main advantages and disadvantages of conventional and intelligent ticketing systems and possible positive outcomes when introducing intelligent transport solutions - namely smart cards or e-ticketing instead of conventional ones (paper tickets and magnetic cards) are analysed in the paper. Two ideas of creating an intelligent ticketing system in an urban public transport are scrutinized. The first is electronic ticket and related equipment, the second - e-ticket and functional areas of it. In the article analysis has also been made on practical outcomes related with introduction of smart cards and e-ticketing. Practical tests and trials as well as a subsequent implementation of electronic tickets have proved unchallenged advantages of contactless smart cards against the contact ones. Nevertheless, a new age of modern technologies calls even for more effective solutions - namely virtual-ticketing systems that might be achieved through introduction of mobile technologies. Therefore, the main focus in the paper is made on the analysis of e-ticket.
\end{abstract}

Keywords: Contact, contactless, dual-interface smart cards, card reader, e-ticket, Bluetooth, SMS, Interactive Voice Response call centers.

\section{Introduction}

A huge potential of intelligent transport systems (ITS) to provide solutions for public transport is highly recognized [1]. This system aims at facilitating seamless transport of people and goods [2]. In a broad sense, the intelligent transport systems in public transport encompass a different type of wireless and wireline communications - based information, control and electronics technologies integrated into public transport system [3]. These technologies might be integrated into the infrastructure of transportation system or/and into urban public transport vehicles and are aimed at reducing time of journeys, monitoring and managing traffic flows, ensuring safety and security at vicinities of stations, on streets, roads and in vehicles themselves, as well as speeding up journeys, improving quality of urban public transport services, planning a multimodal journey, saving time and costs, reducing congestion, providing passengers with real-time traffic information, alternative routes, etc. Intelligent transport systems in an urban public transport might be briefly described as the systems of means to achieve sustainable, safe, environmental friendly and qualitative urban public transportation by applying advanced information and communication technologies. When it comes to ticketing systems, first of all one may think of the most innovative solutions like the smart card ticketing, e-ticketing, state-of-the-art ticketing equipment (ticket vending machines (TVM) card readers), etc. Hence, these solutions are analyzed in the article.

\section{Conventional and intelligent ticketing solutions in public transport systems}

The conventional ticketing system with ordinary paper tickets and mechanical punches that are used to validate paper tickets is still effective in many cases and not necessarily has to be changed into more innovative ones - magnetic tickets, smart card ticketing, etc. This is still applicable approach in urban public transport systems in developing countries, as well as in cities, where urban passenger transport renders exceptionally very clear social function. The main and a very serious disadvantage of such system is that in spite of several slight drawbacks it has one, which is considered as very important one when creating an efficient transport system-mechanical punching has nothing to do with optimization of routes - the possibility to track certain traffic flows, to follow transportation links of passengers is lacking. 
The diagram below briefly indicates the main advantages and disadvantages of different ticket systems that are used in urban public transport systems (Table 1).

Although there are just some features compared in the table, one can easily see the serious drawbacks of the paper tickets system in comparison with all others. No mathematical computing to optimize the urban transport system might be used because of limited possibilities of paper ticket system. Physical pro- tection issues, i.e. falsification of paper single tickets or passes are also relevant [4]. But there are some simple ways developed to prevent falsification, for instance paper tickets in Vilnius are covered with double strings, one of which gleams under the ultraviolet rays, and the second is visible under daylight [5]. Of course, passes have a higher protection level. And the most progressive solution is introduction of so called e-ticketing approach [6].

Table 1. Comparison of ticket types

\begin{tabular}{|c|c|c|c|c|c|c|}
\hline No & \multicolumn{2}{|c|}{ Type of ticket } & Validating & Advantages & Disadvantages & $\begin{array}{c}\text { Application in Intelligent } \\
\text { transport systems and } \\
\text { services approach }\end{array}$ \\
\hline 1 & \multicolumn{2}{|c|}{ Paper tickets } & $\begin{array}{l}\text { Mechanical or } \\
\text { electromechanical } \\
\text { punching }\end{array}$ & $\begin{array}{l}\text { Cheap to produce. } \\
\text { Easy to use. } \\
\text { In a case of improve- } \\
\text { ment of systems - } \\
\text { costs of withdrawing } \\
\text { are comparatively low }\end{array}$ & $\begin{array}{l}\text { Weak protection, risk of } \\
\text { falsification. Not multi- } \\
\text { functional. } \\
\text { Not effective for under- } \\
\text { ground urban transport. } \\
\text { Does not allow tracking } \\
\text { of passenger flows, } \\
\text { boarding and disembark- } \\
\text { ing }\end{array}$ & Incompatible \\
\hline 2 & \multicolumn{2}{|c|}{$\begin{array}{c}\text { Paper daily, } \\
\text { weekly, monthly, } \\
\text { quarterly, tourist } \\
\text { passes }\end{array}$} & $\begin{array}{l}\text { Generally no } \\
\text { punching }\end{array}$ & Simple, easy to make & Falsification & Might be compatible \\
\hline 3 & \multicolumn{2}{|c|}{$\begin{array}{l}\text { On-board single } \\
\text { paper tickets }\end{array}$} & $\begin{array}{l}\text { Ordinary punching } \\
\text { or no punching }\end{array}$ & $\begin{array}{l}\text { Advantageous mainly } \\
\text { for passengers }\end{array}$ & $\begin{array}{l}\text { If driver sells - time is } \\
\text { wasted. Usually are } \\
\text { charged more than buy- } \\
\text { ing tickets in advance }\end{array}$ & $\begin{array}{l}\text { Applicable, though not } \\
\text { recommended }\end{array}$ \\
\hline 4 & \multicolumn{2}{|c|}{$\begin{array}{l}\text { Paper/plastic } \\
\text { cards/tokens with } \\
\text { magnetic strip (or } \\
\text { two strips) - single } \\
\text { use and passes }\end{array}$} & $\begin{array}{l}\text { Card readers - } \\
\text { contact validation }\end{array}$ & $\begin{array}{l}\text { Better protected than } \\
\text { those made of paper. } \\
\text { More durable. Infor- } \\
\text { mation gathering } \\
\text { options. } \\
\text { Very thick and light }\end{array}$ & $\begin{array}{l}\text { Need for contact punch- } \\
\text { ing. Risk of disfunction- } \\
\text { ing or failure on readers. } \\
\text { Magnetic strip becomes } \\
\text { vulnerable to stronger } \\
\text { crease or other contact }\end{array}$ & $\begin{array}{l}\text { Might be duplicated for } \\
\text { random travellers or tour- } \\
\text { ists that do not need elec- } \\
\text { tronic tickets if the mag- } \\
\text { netic ticketing system had } \\
\text { been introduced before } \\
\text { launching the electronic } \\
\text { one }\end{array}$ \\
\hline \multirow[t]{3}{*}{5} & \multirow{3}{*}{ 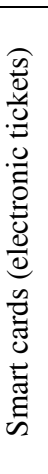 } & $\begin{array}{c}\text { Contact } \\
\text { smart } \\
\text { cards/electro } \\
\text { nic tick ets }\end{array}$ & $\begin{array}{l}\text { Insertion into card- } \\
\text { reader or terminal }\end{array}$ & \multirow{3}{*}{$\begin{array}{l}\text { Very convenient vali- } \\
\text { dating. Gives data of } \\
\text { passenger traffic } \\
\text { flows, useful for opti- } \\
\text { mization of routes } \\
\text { according to the data } \\
\text { received. } \\
\text { Very multifunctional } \\
\text { application of smart } \\
\text { cards (the same card } \\
\text { might be used for } \\
\text { parking, library, } \\
\text { shopping, etc.) }\end{array}$} & \multirow{3}{*}{$\begin{array}{l}\text { Expensive to introduce. } \\
\text { Risk of fake smart } \\
\text { cards - tickets still } \\
\text { exists. } \\
\text { Transaction time of } \\
\text { contact smart cards is } \\
\text { longer than those of } \\
\text { contactless ones }\end{array}$} & \multirow[t]{3}{*}{$\begin{array}{l}\text { Intelligent solution. } \\
\text { Well functioning and fast } \\
\text { developing ticketing sys- } \\
\text { tem }\end{array}$} \\
\hline & & $\begin{array}{l}\text { Contactless } \\
\text { smart card/ } \\
\text { electronic } \\
\text { tickets }\end{array}$ & $\begin{array}{l}\text { Remote scanning, } \\
\text { contacless validat- } \\
\text { ing }\end{array}$ & & & \\
\hline & & $\begin{array}{l}\text { Dual inter- } \\
\text { face cards } \\
\text { and combi- } \\
\text { cards }\end{array}$ & $\begin{array}{l}\text { Allow both ways of } \\
\text { validation }\end{array}$ & & & \\
\hline \multirow[t]{3}{*}{6} & \multirow{3}{*}{$\frac{\widetilde{0}}{\stackrel{0}{0}}$} & SMS-ticket & \multirow{3}{*}{$\begin{array}{l}\text { Via Bluetooth of } \\
\text { mobile phone, } \\
\text { palms, PC's. Con- } \\
\text { tactless validating }\end{array}$} & \multirow{3}{*}{$\begin{array}{l}\text { Ticketless or printing } \\
\text { on request system. No } \\
\text { cash payment. Safe } \\
\text { payment, convenient } \\
\text { use }\end{array}$} & \multirow{3}{*}{$\begin{array}{l}\text { System should be well } \\
\text { organized and main- } \\
\text { tained. Expensive to } \\
\text { introduce. Lots of special } \\
\text { technical requirements } \\
\text { both for passengers and } \\
\text { transport operators }\end{array}$} & \multirow{3}{*}{$\begin{array}{l}\text { The most progressive } \\
\text { solution of ITS application } \\
\text { in ticketing system. } \\
\text { Multifunctional and effec- } \\
\text { tive. To be introduced in } \\
\text { the nearest future in many } \\
\text { leading cities }\end{array}$} \\
\hline & & $\begin{array}{l}\text { WAP page - } \\
\text { ticket }\end{array}$ & & & & \\
\hline & & $\begin{array}{l}\text { Printed on } \\
\text { request }\end{array}$ & & & & \\
\hline
\end{tabular}




\section{Smart card ticketing solutions}

Smart cards were invented and patented in the 1970s. The most common applications are - credit cards, electronic cash, computer security systems, wireless communication, loyalty systems, banking, and personal identification cards [7]. The combinations are also widely applicable, hence this means that the same card might be used for several purposes (as indicated in the table - not only as electronic ticket, but also parking card, etc). In recent years, smart cards have been widely introduced into transport ticketing systems. The main difference from the magnetic strip cards is that the smart card contains an embedded microprocessor instead of magnetic strip. The microprocessor is under golden contact pad on one side of the smart card. This is used for security.

The technology of the smart cards with integrated chips allows contactless validating.

Smart cards can be pre-loaded with certain monetary value, depending on the passengers needs. The smart card usually needs to be scanned for less than half a second, and can be used from inside a wallet, purse or even not taking it out from the pocket [8]. Contactless smart cards allow for communications at distance up to $10 \mathrm{~cm}$ (standard ISO/IEC 14443). Some contactless smart cards, as ISO 15693 allow communications at distance up to $100 \mathrm{~cm} \mathrm{[7].} \mathrm{The} \mathrm{most} \mathrm{popular} \mathrm{standard} \mathrm{-} \mathrm{ISO} 14443$ has several standards of which standards "A" and "B" are two most widely used standards in public transport systems.

Working principal of contactless smart cards is shown in Fig 1.

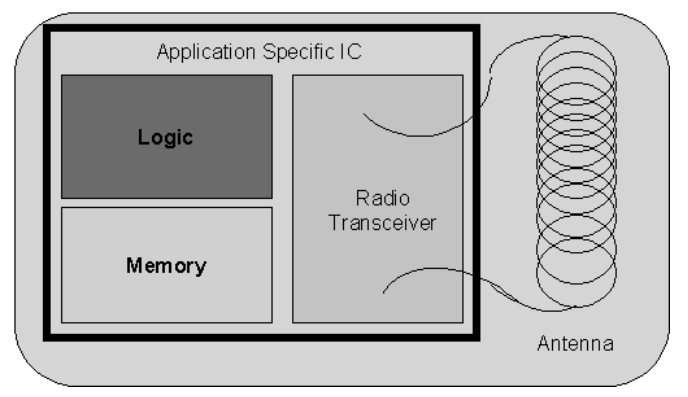

Fig 1. Structure of contactless smart card

There are two blocks - logic and memory block, radio transceiver (transmitter-receiver) and antenna. The present technology allows reaching a very short transaction time, thus making the validation process very quick, what is very important when opening turnstiles at metro stations (Fig 2).

Similarly to contact smart cards, contactless smart cards also do not have a battery. Instead they have a built-in inductor to capture some of the inci- dent radio -frequency interrogation signal, rectify it and use it to power card's electronics.

The value is possible to load using debit or credit cards as well as cash through dedicated machines at metro stations, more important stops and junctions. The smart cards are rechargeable and this is the main advantage of saving time. Loading through internet - online or SMS (stands for short message services), WAP (wireless application protocol) services, also over the phone is often possible [9].

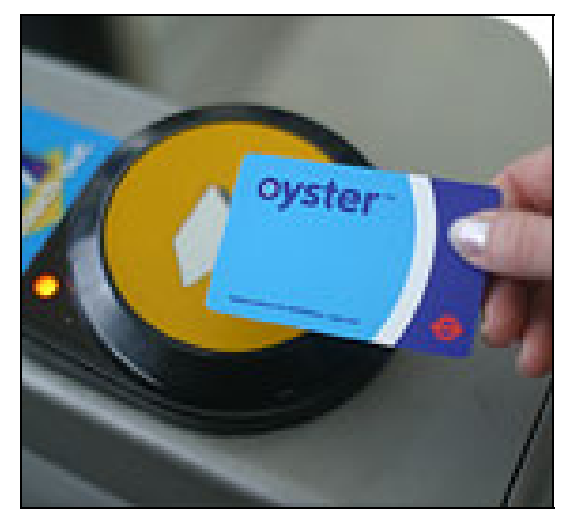

Fig 2. Validation of contactless smart card

Rechargeable smart cards are intended for constant use. There are also disposable smart cards that have advantages for casual passengers, tourists and business travellers.

In fact, smart cards help in many cases avoiding queues, but they are more related with convenience for passengers in terms of pre-loading, easy validation, multifunctional use as well as for public transport authorities, in terms of transport planning, route optimization, security, elimination of fraud and violation of transport rules.

Both contact and contacless cards and their readers can be easily fitted for the public transport ticketing. The main concern is a price of all system to be introduced. In fact, in case of smart cards usage in public transport systems, contactless cards are favourable. Where hostile environmental conditions exist, such as when the reader is exposed to heavy rain or when contaminants are present, contactless technology offers a significant advantage over any contact technology.

Contactless readers are also more resistant to tampering and vandalism, and the lack of moving mechanical parts (e.g., landing pins or read heads) significantly reduces and simplifies maintenance [7].

The combi-card is a quite recent innovation in smart card technology that combines the characteristics of both the contact and contactless cards, i.e. they employ both contact and contactless technology in one card. Combi-cards can also contain two different types of chips in contrast to a dual-interface 
card where a single chip manages both functions. These cards are also used in public transport systems.

\section{Principle of E-ticketing}

Many innovative systems aimed at paying public transport fares have been developed. One of these is a payment over portable devices and namely the most effective and convenient is a payment over mobile phones. The potential of e-ticketing through portable devices (according to surveys, approx. 90 per cent of passengers carry cell phones [6]) has been explored also in other transport services, for instance - to pay motorway tolls, parking fares, bridge tolls, ferry services, etc.

A simplified general scheme of e-ticketing in an urban public transport is shown in Fig 3 [6].

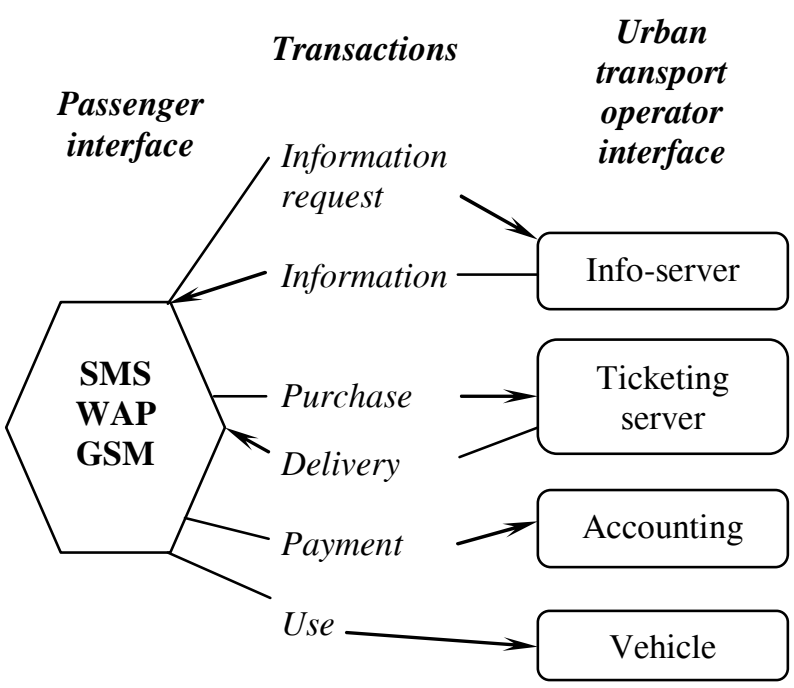

Fig 3. A generic example of e-ticketing

The e-ticket can be checked by inspectors just by reading an SMS message to prove the payment and validation of ticket via portable device (options of validation are scrutinized in the next chapter). Thus goes for journeys by bus, trolleys, light metro or tram. In the case of necessity to access metro or city rail stations, e-ticketing might be performed via Bluetooth technologies to open and pass a turnstile [2]. While Bluetooth phones are still in limited use, for the time being this remains as a perspective option.

\section{E-ticketing in practice}

A bright future for e-ticketing has been proven by TELEPAY project. TELEPAY - the project aimed at establishing the technical, legal and commercial feasibility of a purchase and payment system for virtual e-ticket through mobile phones, using SMS, WAP and short range communication tech- nologies. This system that started in July 2001 and lasted until December 2002 was funded through the European Commision's Information Society Directorate General, coordinated by ERTICO (European Road Transport Telematics Implementation Coordination Organisation) [10].

Tested in 4 cities, namely Berlin in Germany, Rome in Italy, Turku in Finland and Paris in France the project showed a huge potential of e-ticketing. The outcomes of the TELEPAY project served for the further improvements of innovative solutions related with e-ticketing in public transport systems.

The mentioned project identified the main system requirements. Taking into account the generic system architecture, a common technological (communication) platform based on SMS-WAP was used in those cities. In the case of closed systems, a shortrange communication interface was used to open the barriers/turnstiles. Short-range communication was used for the validation of the e-ticket. Payment was performed through the telephone bill or using prepaid SIM (Subscriber Identity Module) cards [11].

A generic model proposed by Siemens Mobile Company for TELEPAY project is shown in Fig 4 (hexagons indicate consecutive steps) [10].

As you can see from the model, passengers have several choices for getting e-ticket: Using technologies of mobile phone, one can use these services provided by GSM (the Global System for Mobile communications) networks:

- SMS (Short Message Service), which allows transmission of message containing information on e-ticket (SMS has to be no longer than 160 alphanumeric characters) [11];

- EMS (Enhanced Message Service) - a standard that allows transmitting icons, sounds or other rich content messages.

- MMS (Multimedia Message Service)- a standard that will replace SMS and EMS.

- WAP - (Wireless Application Protocol) - an open specification, that allows users to instantly access and interact with information and mobile services.

- GPRS - (General Packet radio Service) - a non-voice service that allows information to be sent and received in network.

- Bluetooth - power-efficient low-cost radio system designed to interconnect mobile phones, computers, notebooks, palms and other devices.

- Infrared - low cost interconnection standard that supports point-to-point user model.

As it was mentioned before, different services might be used for different goals - i.e. WAP for information retrieval, Bluetooth - for fast opening of turnstiles, SMS, MMS for getting e-ticket on screen of mobile phone, etc. 


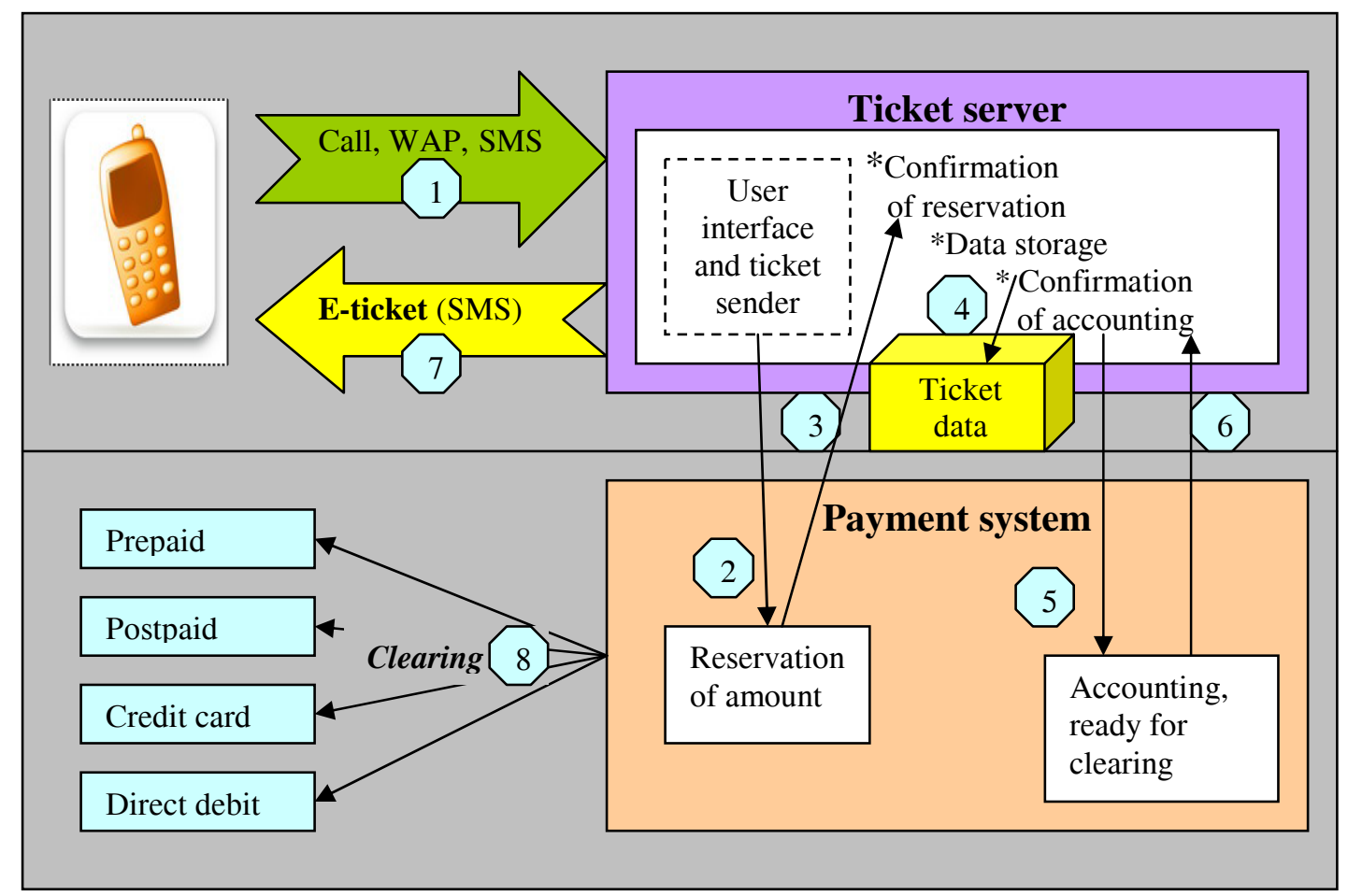

Fig 4. TELEPAY solution of e-ticket system

Further the analysis of deployment of these functions is provided in a resumptive scheme below. Mobile ticketing system covers these 6 functional areas (Fig 5):

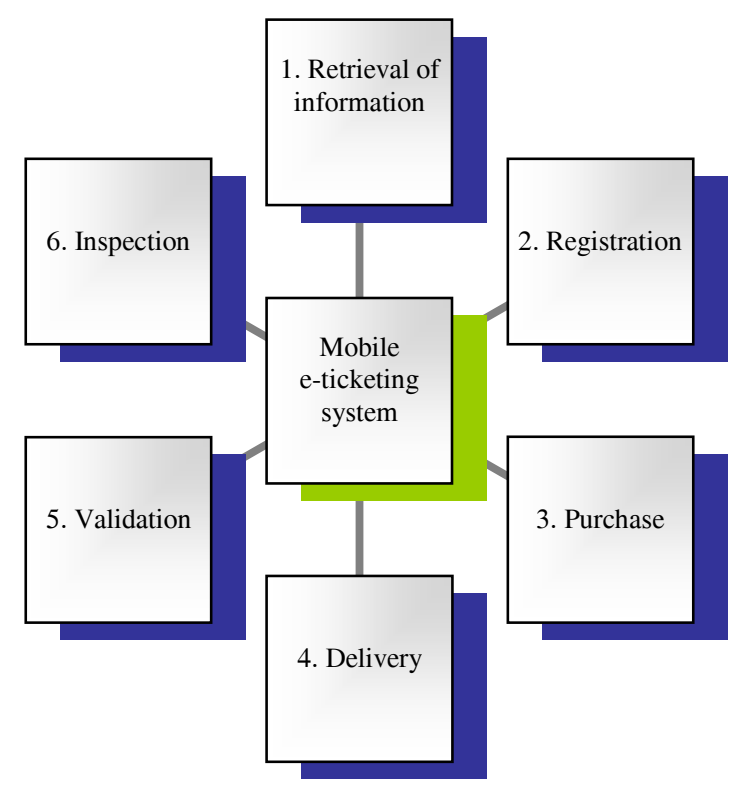

Fig 5. Functional areas of mobile e-ticketing system

1. Retrieval of information concerning the necessary information on ticket type, fares, discounts, might be performed over a mobile phone by searching WAP or sending a SMS query. This information can be supported by valuable information on ticket validation zones and period, information on how to reach the stop or terminus, besides, after the retrieving the previous information, a passenger should have possibility to easily purchase the ticket. Other ways to get information are to deploy Interactive Voice Response (IRV) call centers, where information about ticket is provided automatically into general questions [11].

2. The registration might be a necessary step in some mobile ticketing systems before purchase of a ticket. This is necessary when efficient inspection of a ticket is needed. It might also be a necessary step for legal reasons to allow a billing of nontelecommunication services for mobile operators or transport companies (operators).

For the registration step, the passenger may use the same channel as for information retrieval. This method is applicable if the registration does not require a signature, or a handover of electronic ID which is later used to inspect the ticket [10].

Passengers may also make a registration at ticket sale-points by filling out certain forms or perform an Internet registration at transport company's website where one must fill out an electronic form, prove identity and give mobile phone number. 
3. Purchase. This functional area has to be very well functioning: a payment ought to be as convenient as possible in order to require the minimum effort on the passenger's side (Fig 6).

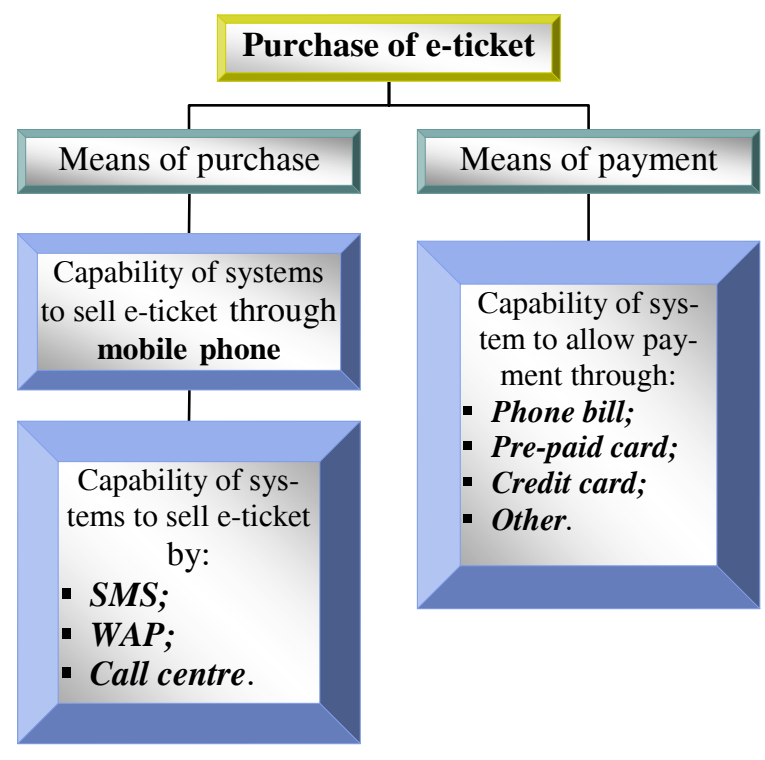

Fig 6. Purchase of e-ticket

As we can see from the picture, the e-ticket sales-system shall be capable to allow different means of payment and purchase in order to match the requirements of all passengers. If the passenger chooses to use WAP option, he/she browses with his/her WAP to a transport operators WAP site, searches for ticket and orders the ticket (the WAP server can identify the WAP device and remember the order) [11]. In a case of SMS purchase - a passenger sends an SMS with certain syntax to the ticket vendor. In the SMS, all information to generate an e-ticket, as for instance, ticket type, fare, zone, travel time, age, social status, etc., is provided. After that, a vendor sends back a confirmation request SMS in which all information is displayed including security and control aspects, and requests the passenger to confirm the purchase. Finally, after a positive acknowledgement e-ticket is sent via SMS to the passenger. In the case of purchase via Call center, the passenger calls a special number which connects him with a Call center. Then, he/she is asked to choose ticket type. After he/she has chosen the type of ticket, then the information on ticket fare is provided, and passenger is asked if he wants to buy the ticket. With a positive answer the customer gets the e-ticket and is charged for the price agreed. The same true is also for automatic call center, when passenger is guided by automated announcements.
4. Delivery of e-ticket depends on a method of purchase. In the TELEPAY project, two main scenarios of delivering the ticket might be distinguished:

- Ticket is entirely "with" passenger.

- Centrally stored e-ticket.

In the "a" scenario, it is not necessary to store passenger information at the ticket vendor. If a demand for more reliable system arises, then the ticket information can also be stored at the ticket server.

In the "b" scenario the ticket is centrally stored in a transport operator's database. The passenger may, but does not necessarily need, get an SMS message for confirmation. SMS message, containing a virtual ticket is not the only one option. The diagram below indicates other forms of e-ticket (Fig 7).

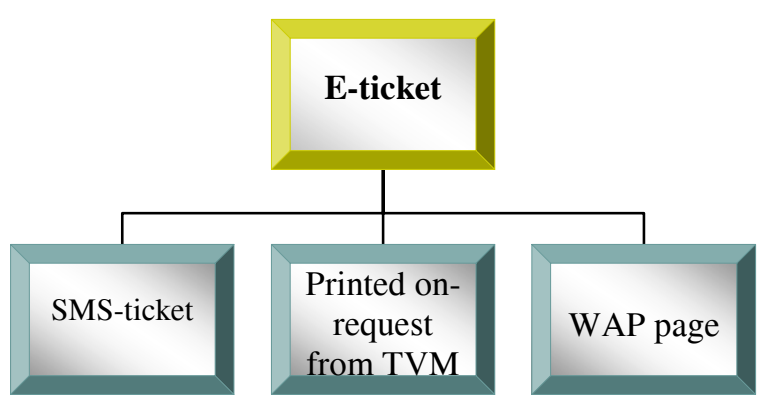

Fig 7. Types of e-ticket

The main perplexities of SMS ticketing are security and delivering failures. The latter problem might be solved by additionally storing an e-ticket in a central database for a defined time in order to prove that passenger had bought a ticket. A minimum requirement in TELEPAY project was to guarantee that 98 per cent of all SMS will be delivered within 10 seconds. As concerns the security issuesthe final work has not been done yet. The main issue here - how to block the resending of e-ticket. One method is to encrypt a special string along with a ticket, which is randomly created, valid only one day and known only by the ticket inspectors [11]. Second option is to transform e-ticket into a bidimensional barcode.

In the same way as this has been introduced by air transport companies, the ticket might be printed out from the ticket vending machines (TVM), when passenger calls and pays for it with a mobile phone. Passenger may also call a passenger service number and get the e-ticket after he/she identifies the TVM where ticket will be printed and the system 
immediately initiates the ticket vending machine to print it.

WAP page is more a theoretical option rather than practical. Although most WAP phones are able to store several pages in their cache thus taking an advantage of its to use this feature for sending the ticket as WAP page to the passenger, these phones are not able to save the WAP pages permanently. So, if the passenger accesses too many WAP pages after getting the WAP ticket page, this ticket is erased from the cache [11].

5. Validation depends on public transport network type. There are two types:

- open transport network;

- closed transport network.

In the closed transport network the systems can validate the ticket through short-range communication to open tollgate/turnstiles [6].

In the open transport network, short-range communication is an option, but it is not strictly necessary to run the system.

Number of surveys has shown and trials have proven, that a validation by short-range communication is highly acceptable amongst passengers and being so practical (almost everyone carries a phone) it will definitely finds its place in a multimodal public transport systems. Besides, the process tends to be more effective because mobile ticketing system may include validation machines similar to those in use for the paper tickets. The ticket is transferred to the validation machine by means of short-range communications such as Bluetooth or infrared. The validation machine could then either a) forward the ticket data to a server storing the ticket centrally, which then gets updates with the validation data upon entry, or b) modify the ticket and transfer it back to the mobile device. According to high costs of validation equipment, it is economically more profitable to implement multimodal ticketing systems or $\mathrm{sp}$ called single - ticket system [6].

6. For the inspection of e-ticket there are several options (see Table 2).

There are two possible meanings of the functional area of inspection [11]:

- An open system, when personnel of inspection performs random spot checks.

- A closed system, when the inspection is the process of verifying the ticket when letting the customer get out of the closed area.

From a technical point of view and also assessing the level of security and quality, the most effective is barcode scan of e-ticket data. In this case, the
Table 2. Options of inspection of e-ticket

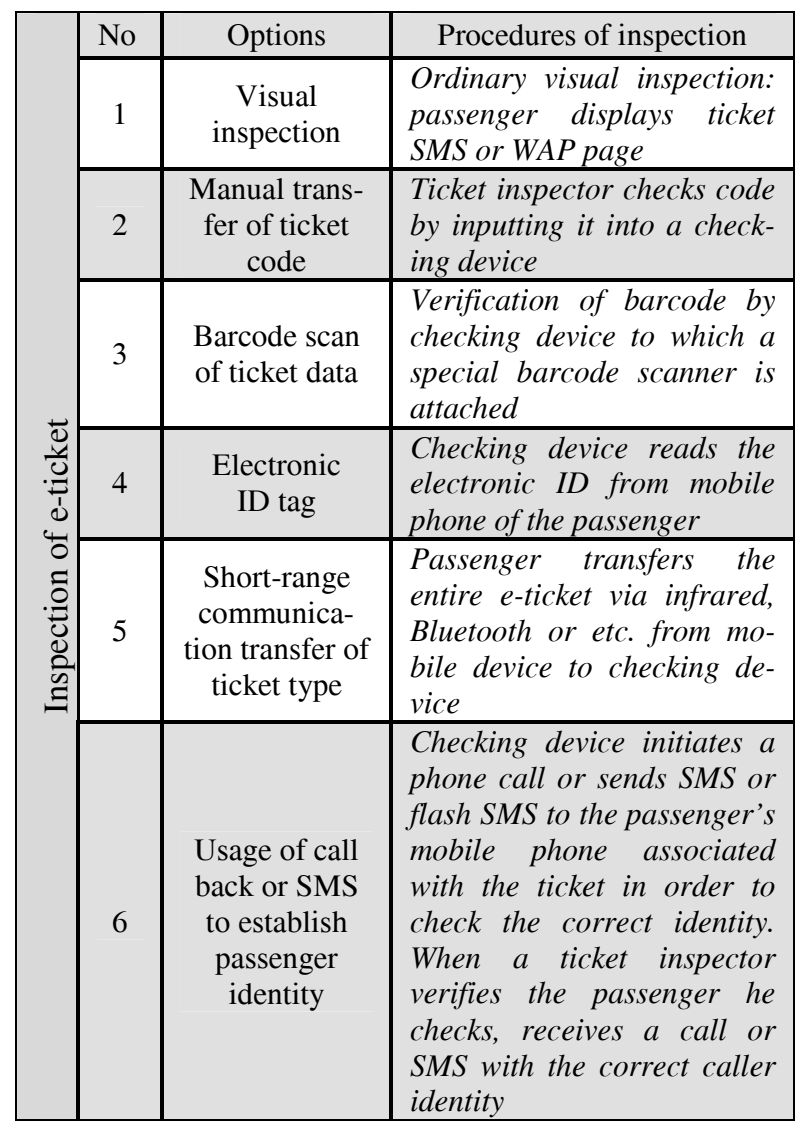

e-ticket shall contain a barcode (e.g. a bidimensional barcode) which can be read from the mobile phone display with a special barcode scanner attached to the checking device. The checking device can then verify that this code corresponds to a valid ticket, either via a wireless online checking connection to the ticket server, or by searching for this ticket in a continually updated cache of all valid tickets.

The outcomes of TELEPAY project made a huge contribution to foster real implementation of e-ticketing systems. After being made operational in the Finnish city of Turku, the TELEPAY concept was later turned into reality in Italy, Rome [12]. The metropolitan in Rome has a fully accessible mobile phone network, thus allowing passenger to use eticket both on surface transport and underground. Travellers to Rome can also benefit from the service due to roaming agreements between mobile phone operators [13].

These practical examples revealed persuasive advantages of e-ticketing: seamless interoperable ticketing, increased revenue due to lower costs for transport and infrastructure operators, less time wasted queuing by passengers, better functioning multimodal urban public transport systems, among others. 


\section{Conclusions}

1. ITS aimed at simplifying of ticketing operations require high investments and thorough analysis. Some technologies are of limited use because of jeopardy of introduction of newer and more effective solutions.

2. The trends of technological development are difficult to forecast and a comprehensive cost benefit analysis is crucial. Despite of uncertainties about obsolescence of electronic equipment in terms of more effective software and introduction of new alternative solutions, ITS have a very high potential to improve urban transport ticketing system.

3. Contactless smart cards and e-ticketing are ones of the fast-track approaches making urban public transport systems intelligent.

4. Easy payment systems for an urban transport are the backbone of seamless solutions of intermodal urban public transport system. Therefore leading public transport operators tend to implement contactless smart card based ticketing systems. Because of their high cost of implementation, those systems that are based on smart card ticketing, can only be cost effective for multimodal journeys. It is crucial to cover as many transport modes as possible, including both ground and underground transport.

5. E-ticketing is based on paperless or "virtual" ticketing system that makes it very attractive and convenient for passengers. This is the most innovative solution, which has already been very successfully applied in urban public transport systems.

\section{References}

1. Intelligent transport systems: intelligence at the service of transport networks. European Commission, Energy and Transport DG. Luxembourg: Office for official publications of the European Communities, 2003. 2 p.

2. White Paper-European transport policy for 2010: Time to decide, European Commission, Office for official publications of the European Communities, Luxembourg, 2001, p. 76-84.

3. The intelligent transportation society of America. "ITS America. Technology transforming transportation. 2004 Annual Report”, 2004, p. 2-14.

4. Intelligent transport systems and services. ITS-part of everyone's daily life. ERTICO - ITS Europe navigation technologies. Brussels, 2002, p. 8, 43-55.

5. Butkevičius, J. Introduction of electronic card system in Lithuanian city passenger transport. Transport and Telecommunication, Vol 7, No 1, 2006, p. 149-155.

6. Butkevičius, J. Modelling of the dependence of travel frequency on the length and duration of a journey. Improvement of city passenger transport systems. Transport, Vol 17, No 6, 2002, p. 223-225.
7. Government smart card handbook. US general services administration, USA. 2004, p. 15-68.

8. Transport for London. London oyster smart card. Press release, August 17, 2005.

9. Smart card ticketing takes major step forward, Media release, July 12, 2005. Victorian State Government, Australia, 2005.

10. Blervaque V (ERTICO). Telepayment system for multimodal transport services using portable phones. TELEPAY - System requirements, ERTICO, Brussels, 2003, p. 1-53.

11. Blervaque V (ERTICO). Telepayment system for multimodal transport services using portable phones. TELEPAY Final report, 2003, p. 5-25.

12. E-government news: IT - E-ticketing system launched for Rome's public transports, European Communities 2005.

13. La Repubblica. Rome, Transport revolution: paying for ticket with SMS (Technologia \& Scienze. Roma, rivoluzione trasporti: il biblietto si paga con un SMS). Roma, Italy. February 24, 2005 (in Italian). 